Swarthmore College

Works

\title{
Wittgenstein On Aspect-Seeing, The Nature Of Discursive Consciousness, And The Experience Of Agency
}

Richard Thomas Eldridge

Swarthmore College, reldrid1@swarthmore.edu

Follow this and additional works at: https://works.swarthmore.edu/fac-philosophy

Part of the Philosophy Commons

Let us know how access to these works benefits you

\section{Recommended Citation}

Richard Thomas Eldridge. (2010). "Wittgenstein On Aspect-Seeing, The Nature Of Discursive Consciousness, And The Experience Of Agency". Seeing Wittgenstein Anew: New Essays On AspectSeeing. 162-179.

https://works.swarthmore.edu/fac-philosophy/260

This work is brought to you for free by Swarthmore College Libraries' Works. It has been accepted for inclusion in Philosophy Faculty Works by an authorized administrator of Works. For more information, please contact myworks@swarthmore.edu. 


\title{
Wittgenstein on Aspect-Seeing, the Nature of Discursive Consciousness, and the Experience of Agency
}

\author{
Richard Eldridge
}

We find certain things about seeing puzzling, because we do not find the whole business of seeing puzzling enough. (PI 212f)

1.

Consciousness or awareness is possessed by at least a wide range of higher chordates. But genuine discursive consciousness is possessed at least in its complex forms - only by human beings. Only human beings can, so it seems, be aware of seeing a given object as this or that, under one or another concept. The ability to be thus aware informs our perception, giving it both a judgmental character and a relation to self-consciousness. We typically see or hear that $x$ is $F$, over and above simply taking in sensations. There is for any one of us always the potential to step back from our conceptually structured, judgmental perceiving so as to become explicitly aware that it is I who have judged that $x$ is $F$ (rather than, say, $G$ ). This openness to awareness of one's own role in judgmental perceiving further opens for us the possibility of a normative question arising. Am I correct so to have judged? This question does not arise for other higher mammals. They do not thus call their own being into question.

Historically, the apparently special character of human judgmental consciousness has motivated a variety of attempts to explain it, including at least Plato's theory of the immortal soul's ability to recollect eternal Forms, Aristotle's theory of nous as actively instancing 
essences both in us and in things, and Augustine's theory of the scintilla animae. Kant proposes, somewhat obscurely, that a spontaneity of reason stimulates the understanding to produce from its own resources the pure or nonempirical concepts of substance and causality that then figure as part of the implicit substructure of the more ordinary empirical concepts we form. ("Cup," for example, is a substance-concept; "break" is a causal verb.)

More recently the leading contenders for an explanation of the fact - if it is a fact - of the special character of human discursive consciousness have been various forms of materialist naturalism: symbolic representations theory and connectionism. Sometimes a generally Kantian stance is naturalized, so that the structure of our sorting practices is "wired in" (no longer the product of a spontaneity, and no longer bound up with the standing possibility of self-awareness), as in Chomsky and other forms of post-Piagetian, naturalistic symbolic representations theory. Sometimes an empiricist-associationist stance is naturalized, and judgmental responsiveness to things is taken to arise only out of networks of neural connections, again without reference to either spontaneity or self-awareness.

When the relations between discursive consciousness, on the one hand, and spontaneity and self-awareness, on the other, are thus broken, then the very idea that we are capable of judging that thus-and-so is threatened. We seem then not to be responsible for what we do, but to be mere sensing and responding animals (like the dogs and frogs with whom we share the earth), incapable of even so much as raising the question whether we are correct to judge as we do. Judgments, structured by concepts, about how things are, are reduced to complexities of purely caused response. This idea - that human judgment does not properly exist as judgment - seems fantastically implausible. But then just what are judgment and discursive consciousness? And how can they possibly arise in us?

Wittgenstein's work - early and late - clearly fits into the tradition of philosophical investigations of the nature and basis of discursive consciousness. The picture theory of meaning in the Tractatus and the analysis of the proposition into simple names corresponding to simple objects are put forward to elucidate how truth-value-bearing propositions and thoughts are possible. "There must be something identical in a picture [whether proposition or thought] and what it depicts, 
to enable the one to be a picture of the other at all." [In Bild und Abgebildetem muss etwas identisch sein, damit das eine überhaupt ein Bild des anderen sein kann.] (TLP 2.161, emphases added.) Here the "must" and "at all" (überhaupt) indicate that the necessity involved is transcendental or conceptual. It is, so the argument runs, not thinkable that genuine representationality and truth value-bearing judgmental structure could be set up otherwise, in thought or in language. Wittgenstein's resolute determination to keep transcendental or purely conceptual investigations - philosophy or philosophical logic - separate from empirical science as the investigation of contingent states of affairs means, however, that no causal-material explanation of what the elements of pictures (in either thought or language) are, and how they interact with simple objects, is on offer. It is a transcendental or logico-philosophical necessity that there are simple names (in thought and in language) that can be arranged in a way that corresponds to (shares a pictorial form with) an arrangement of simple objects. What these simple names (and simple objects) specifically are, and how the relevant correspondences are set up, must take care of itself. That they must exist and must be able to stand in relations of correspondence is, in contrast, something that is necessary in order for there to be truth value-bearing thoughts and propositions at all.

In Philosophical Investigations these specific claims about what is transcendentally or logico-philosophically necessary are subjected to criticism. The full-blooded representationality or judgmental-discursive character of both thought and language are - it is now proposed matters not of any "substructure" of simple names and simple objects lying underneath the surface, but matters rather of words having a role within a public language as a matter of common practice. "This role is what we need to understand in order to resolve philosophical paradoxes" ( $P I \$ 182)$. "A person goes by a sign-post [i.e., is able to use a word, understands] only insofar as there exists a regular use of sign-posts, a custom" ( $P I \S 198)$. "To understand a sentence means to understand a language. To understand a language means to be master of a technique" (PI §199). "'How do sentences manage to represent?' ... Nothing is hidden" (PI\$435).

Once we see this - that nothing but the mastery of a technique laid down in common, public practice could enable one to assert, judge, or state, or to wish, command, hope, fear, or envy, as opposed to having a 
life only of mere sensory awareness - then we are, so it seems, to cure ourselves of our temptation to look for a "deeper" quasi-scientific or metaphysical explanation of discursive consciousness, full-blooded representationality, judgmental awareness, or our life with language. We are, it seems, to stop hunting for the "superlative fact" that underlies and explains these phenomena, to stop groping after "a superexpression" or "a philosophical superlative" that might describe this putatively explanatory superlative fact $(P I \S 192) .{ }^{1}$ Here the role of common practices and techniques in making language meaningful and making propositional attitudes possible remains, for Wittgenstein, a philosophical, logical, or grammatical fact, not simply one empirical fact among others to be investigated and explained causally. The emphasis remains on what must be in place - a technique, a common practice, a custom in using words - in order for there to be discursive consciousness, understanding, judgmental awareness, propositional attitudes, and words with meanings at all.

Notoriously, this stance (especially insofar as it is urged as a thesis or conclusion) has occasioned considerable disappointment and hostility in contemporary philosophy, and for good reason, at least prima facie. Language and discursive consciousness are, at least in their fullblooded forms, specific to biologically evolved human beings; linguistic and cognitive performances are generated by human individuals. Surely there must, it seems, be some further explanation available of the nature and basis of these feats, in the individual and in the species. Indeed, numbers of readers of Wittgenstein have themselves, in the grip of a wish for something deeper, undertaken to go beneath noting our grammar and linguistic practice, in the hope of explaining what makes that practice what it is. As a result we are sometimes told that Wittgenstein himself held that what counts as understanding

\footnotetext{
That Wittgenstein is urging this stance of attention to the ordinary on himself, in the face of his own temptations otherwise, as much as on us as a kind of statable thesis or dogma, but that it is - for him and for us - all but impossible consistently to remain in this stance, and finally that peace in relation to the ordinary comes, when it comes, fitfully and through the dawning of a sense of gratitude for one's human life (rather than via a discovery of its essence) is the argument of my Leading a Human Life: Wittgenstein, Intentionality, and Romanticism (Chicago: University of Chicago Press, 1997), drawing extensively on Stanley Cavell's reading of Philosophical Investigations in The Claim of Reason: Wittgenstein, Skepticism, Morality, and Tragedy (Oxford: Oxford University Press, 1979).
} 
(discursive consciousness) consists in reacting in a way that is simply natural (Stroud), in deciding to do this or that (Dummett, Rorty), in doing what the community has laid down as correct (Kripke), or in fluent conformity to fixed "internal relations" (Baker and Hacker). ${ }^{2}$

Cognitive science of all kinds has not been slow to sketch possible explanations and to undertake to fill in their details through empirical research. As Jerry Fodor cogently remarks, why can't we ask questions such as "What (causally) makes the linguistic form 'red' apply to red objects?"3 It does not so apply in all cultures; it does for us, we who are able to speak English. When we apply the word "red" correctly (or incorrectly), we are doing something. Just what are we doing, and how do we do it? "How does one become "master of a game' (PI $\left.33_{1}\right)$ ?"4

When these questions do not receive any clear address or answer from within Wittgensteinian thinking, then cognitive science and neuroscience, with their material causal explanations, will rush in to fill the gap. Happily, there is a kind of address or answer to these questions - and one quite different from what is envisioned in naturalist, conventionalist, and communitarian misreadings of Philosophical Investigations - in the text of Philosophical Investigations itself, in the discussion of seeing-as in Part II, Section 11 and in related remarks about coming to experience the meaning of a word. These remarks (if we can follow and make sense of them) have considerable promise for filling in a picture of what we are doing when we are judging, understanding, entering into a propositional attitude, ordering, wishing, hoping, or fearing: participating in all the phenomena of discursive consciousness - and a picture that is not "metaphysical" (in referring what we do to something else), material-scientific, naturalist-causalist, or conventionalist.

In order to see just how these remarks offer such a picture and to begin to assess its plausibility, it will be helpful first to turn to the recent work of a cultural-developmental-cognitive scientist (if that is not too much of an oxymoron) who has drawn extensively on

2 See Eldridge, Leading a Human Life, 91-112 for description of these readings, criticism of them, and an alternative.

3 See Jerry A. Fodor, The Language of Thought (New York: Thomas Y. Crowell, 1975), 2-9 for this argument in favor of the sense of this causalist question.

${ }^{4}$ Compare the discussion of Fodor's causalism in Eldridge, Leading a Human Life, $15^{\circ}$. 
Wittgenstein's work on seeing-as. In The Cultural Origins of Human Cognition, Michael Tomasello has surveyed the existing studies of primate "cognition" and of human cognitive development. ${ }^{5}$ Drawing on these studies as well as on Wittgenstein, Tomasello has developed a persuasive account of just what we do in learning language and in learning to understand under concepts. This account is not simply causalist, not simply conventionalist, and not in any sense homuncularist-intellectualist. After tracing Tomasello's account of the details of this learning process, we will then be in a position to turn to the details of Wittgenstein's discussion of seeing-as, ready to be alert both to how seeing-as plays a fundamental role in learning to understand and to how seeing-as and learning to understand are things that we do, as opposed to things that merely happen in us. We will be able then to follow Wittgenstein's thoughts about the (co-)dawning of discursive consciousness and agency and about the human circumstances, plights, and possibilities that come with these dawnings.

2.

Tomasello's story runs as follows. "Individual human beings possess a biologically inherited capacity for living culturally." ${ }^{6}$ To say that they have a (second-order) capacity, rather than an explicit first-order ability, 7 for living culturally is to say that they are the kinds of beings who can learn to produce fluent, conceptually structured, cultural performances, not that they come into the world already explicitly able to produce them. There is a biological contribution to becoming a concept-mongering, acculturated being, but that contribution does not take the form of already possessing concepts in any way.

The development of explicit linguistic, conceptual, and cultural abilities then depends crucially on ontogenetic-developmental

\footnotetext{
5 Michael Tomasello, The Cultural Origins of Human Cognition (Cambridge: Harvard University Press, 1999). Many of the studies cited by Tomasello are his own; others are by eminent researchers including Savage-Rumbaugh, Rumbaugh, Nelson, Premack, Woodruff, Meltzoff, and Gopnik.

6 Ibid., 53 (emphasis added).

7 Aristotle distinguishes capacities or second-order abilities to acquire abilities from explicit, first-order abilities in Physics 8.4 .255 azo ff.
} 
processes "by which human children actively exploit and make use of both their biological and cultural inheritances." 8 These

historical and ontogenetic processes ... are enabled but not in any way determined by human beings' biological adaptations for a special form of social cognition. ... It is these processes, not any specialized biological adaptations directly, that have done the actual work in creating many, if not all, of the most distinctive and important cognitive products and processes of the species Homo sapiens. ${ }^{9}$

Two crucial dimensions of these processes are that they involve children actively doing something, and that they require and involve identification with other human beings as havers of a point of view. Members of other species likewise identify with conspecifics, and they may "pick up" behaviors via patterning, in the way that songbirds, for example, will pick up a species-typical song. But the identification of human children with other human beings is, in contrast, both deeper and point-of-viewrelated. "Human beings 'identify' with conspecifics more deeply than do other primates. This identification is not something mysterious, but simply the process by which the human child understands that other persons are beings like herself - in a way that inanimate objects are not, for example - and so she sometimes tries to understand things from their point of view." ${ }^{\circ}$ Hence the process of the development of linguistic and cognitive skills on the part of the child is a process of sociogenesis; it requires other havers of points of view. So-called "wild children," or children otherwise biologically growing up under conditions of severe deprivation of human interaction, do not develop sophisticated linguistic and cognitive skills; many autistic children master them only in part; and other species do not master them at all. ${ }^{11}$

Other primates do respond to their environments in sophisticated ways that involve both rich sensory awareness and differential response or classificatory abilities. They remember the locations of things in their environment, assume object persistence, match small numerosities, recognize and represent relations of kinship and rank, cooperate in problem-solving tasks, and more. ${ }^{12}$ What they do not do, however,

\footnotetext{
8 Tomasello, Human Cognition, 11, emphasis added.

9 Ibid.

10 Ibid., 14.

11 Ibid., 14, 8.

12 Ibid., 16-17, 19.
} 
is "view the world in terms of ... underlying causes and intentional/ mental states. ... Nonhuman primates are themselves intentional and causal beings, they just do not understand the world in intentional and causal terms. ${ }^{.13}$ Underlying their failure so to understand the world is the fact that nonhuman primates "do not participate in extended joint attentional interactions in the same way as human children." ${ }^{\prime 4}$

In contrast, children engage soon after birth in "protoconversations" with adults, that is, "social interactions in which the parent and infant focus their attention on one another - often in a face-toface manner involving looking, touching and vocalizing - in ways that serve to express and share basic emotions." ${ }^{15}$ By the age of nine to twelve months, children engage in "joint attentional behaviors that seem to indicate an emerging understanding of other persons as intentional agents like the self." ${ }^{16}$ Within these joint attentional behaviors, a "referential triangle of child, adult, and the object or event to which they share attention" is set up. ${ }^{17}$ Crucially this referential triangle involves the joint focusing of attention on a thing or event construed in a certain way within the game. That (the soft plush item on the floor) is a rabbit, or Pooh's friend, or the one who is resting from hopping, or the toy Aunt Sadie gave you, as the context may be.

One comes - all at once - to be able to use words to refer to things, and distinctly and self-consciously to conceive of things in particular ways, in and through participation in joint attentional behaviors and referential triangles. Hence "linguistic reference is a social act in which one person attempts to get another person to focus her attention on something in the world" that has been construed in a certain way within the context of the scene..$^{18}$ As the child moves

13 Ibid., 19 .

${ }^{14}$ Ibid., 36.

15 Ibid., 59. Compare R. G. Collingwood on the development of personhood, point of view having, and cognitive and linguistic skills in the child through a complex play of contestation and expression with an adult, in The Principles of Art (Oxford: Clarendon Press, 1938), 239-41.

16 Tomasello, Human Cognition, 61.

17 Ibid., 62. Compare Donald Davidson on referential triangles in "The Second Person" and "The Emergence of Thought," Subjective, Intersubjective, Objective (Oxford: Clarendon Press, 2001), 107-21 (see especially 117-21) and 123-34 (see especially 128-29).

18 Tomasello, Human Cognition, 97. 
within these scenes from an initial biologically supported mimicry and into more flexible and evolving play, in which objects are construed and reconstrued as this or that, genuine, self-conscious pointof-view-having develops. The child becomes aware that this object can be construed- or conceived-as this or that, in this or that changing context of goals, aims, and emotions, and so she comes to be aware both of the multiple kinds of things objects are, and of herself as a construer and conceiver. ${ }^{19}$

What Tomasello calls the internalization of a linguistic symbol, which is initially used by the adult within a joint attentional interaction, as a symbol involves the learning all at once of words, concepts (construals of the ways things are), point of view, and of self and other as havers of points of view. This internalization takes the child well beyond the kinds of merely perceptual representations that she otherwise shares with other higher chordates:

As the child internalizes a linguistic symbol - as she learns the human perspectives embodied in a linguistic symbol - she cognitively represents not just the perceptual or motoric aspects of a situation but also one way, among other ways of which she is aware, that the current situation may be attentionally construed by "us", the users of that symbol. The way that human beings use linguistic symbols thus creates a clear break with straightforward perceptual or sensory-motor representations, and it is due entirely to the social nature of linguistic symbols. ${ }^{20}$

Genuine linguistic symbols are hence something more than apt response-based sensory-perceptual representations. Instead they have, in Tomasello's phrasing, "human perspectives embodied" in them:

In different communicative situations one and the same object may be construed as a dog, an animal, a pet, or a pest; one and the same event may be construed as running, moving, fleeing, or surviving; one and the same place may be construed as the coast, the shore, the beach, or the sand - all depending on the communicative goals of the speaker. ... As perspectivally based cognitive representations, then, linguistic symbols are based not on the recording of direct sensory or motor experiences, as are the cognitive

19 Compare Cavell on language-learning in "Learning a Word," The Claim of Reason, $169-80$.

2o Tomasello, Human Cognition, 126. 
representations of other animal species and human infants, but rather on the ways in which individuals choose to construe things out of a number of other ways they might have construed them, as embodied in the other available linguistic symbols that they might have chosen, but did not. ${ }^{21}$

Genuine symbolic representations or linguistic symbols (as opposed to perceptual representations only) are, then, all at once public, intersubjectively shared, and perspectival, i.e., saturated with "embodied construals" of how things are, which are salient in relation to certain goals, purposes, and contexts of joint attention. Unlike either mere perceptual representations or animal signals, they embody an available construal of things, and they enable genuine communicative action through their use. The availability of these symbolic representations to a now developed genuine subject, in possession of explicit cognitive and linguistic skills, marks the difference, in Aristotelian terminology, between a being with phantasia or sensory awareness alone, and a being for whom phantasia is informed and structured by nous, whose awareness is then fully discursive. But this difference in the structure of awareness - the emergence of the very life of a person - is brought about neither by the agency of nous, nor by biology plus causal conditioning alone, but instead by a sociogenetic process involving the development from mimicry to participation in joint attentional interactions. Full-blooded, discursively structured consciousness comes by way of developing through attentional interactions the skill of using genuine symbolic representations that embody construals.

3 .

At first blush, there are significant differences between Tomasello's story of the development of discursive consciousness, self-consciously influenced by Philosophical Investigations though it is, and Wittgenstein's investigations into aspect-seeing. Tomasello's account is built up out of observations available in the primate observation and child development literatures. That account is part of an empirical inquiry into what is going on as a matter of fact. Wittgenstein, in contrast, reminds

${ }^{21}$ Ibid., 8-9. 
himself (and us) that "Our problem is not a causal but a conceptual one.... What is at issue is the fixing of concepts [Begriffsbestimmungen]" (PI 203e, 204g).

Looked at more closely, however, these differences are less striking. To begin with, Tomasello's story is not itself derived from experimental results, but is instead developed out of conceptually selfconscious observation of what children (and primates) do (and don't do). What we do in learning language is neither reduced to, nor explained by, purely material processes, according to Tomasello. What we do involves the development and exercise of an ability (based on a prior innate capacity) in actual practice. Nothing is hidden, one might say.

Conversely, Wittgenstein connects his investigation of aspect-seeing more closely with the learning of language than might initially meet the eye. He remarks at one point on "a game played by children: they say that a chest, for example, is a house; and thereupon it is interpreted as a house in every detail. A piece of fancy is worked into it" (PI 206e). This remark suggests that the appearance of fancy (invention; Erfindung) within game-playing in the life of a child is akin to seeing an aspect. When we then further notice the remark that seeing an aspect bears "a close kinship with 'experiencing the meaning of a word'" (PI 210c; see also 214d), then the suggestion is not far off that it is by exercising fancy (inventiveness, imagination) within the context of game-playing that children come to learn language at all (by catching on to the aspects of things that are "embodied" in words).

Even the remark about the fixing of concepts (PI 204h) itself admits, in context, of two different, compatible readings. What is at issue is, first, what the concept (or various concepts) of seeing and visual experience are - that is, what it makes sense, conceptually, to compare these phenomena to, and how to understand them - but also, second, how concepts get fixed at all within our seeing: how does our seeing itself come to be discursively structured, how do concepts get fixed (determined; bestimmt) in it.

This latter reading is decisively reinforced, repeatedly, throughout the discussion of seeing an aspect. That discussion begins by noting a difference between "two uses of the word 'see'": one in which one might report having had a piece of sensory awareness by saying, "I see this," accompanied by a description or drawing or copy; and one in 
which one sees "a likeness between these two faces" - i.e., two things (faces) are compared with one another (PI 193a). This difference between two kinds of seeing resembles the difference in English (and German) between "see" (sehen) as it takes an object accusative ("I see $x$ "), and "see" as it takes a propositional accusative ("I see that $x$ is $F$ "). The achievement described in the latter, propositional accusative form is necessarily conceptually structured in a way that the former having of a visual impression need not be. ${ }^{22}$ (A frog can see the fly, but not see that that is a fly - does it see that it is a bluebottle or a May fly? - and cannot be implicitly aware of itself as so seeing. It cannot report the content of its awareness in the form of a proposition, even to itself.) Wittgenstein notes that there are two kinds of seeing in question here: what one might call seeing as mere visual awareness, and "discursive" seeing or seeing informed by conceptualization, wherein a noticed aspect can be reported. About noticing an aspect, he observes that "It must be possible to give both remarks [both 'But this isn't seeing!' and 'But this is seeing!'] a conceptual justification" [Beide müssen sich begrifflich rechtfertigen lassen]: both ways of speaking must admit of being conceptually justified; both must be regarded as conceptually legitimate $(P I$ 203c). And this is as much as to say that there are two concepts of seeing that must be distinguished. One is the having of visual awareness, without any conceptualization; the other involves "a modified concept of sensation" (einen modifizierten Empfindugsbegriff) (PI 2ogh), where sensing (seeing and hearing) include that one notices or recognizes something (for example, recognizes a face as timid: "ihn [ein Gesichtseindruck] als furchtsam ... erkennt" [PI 209h]). This latter kind of sensation involves having concepts as part of its very structure, in a way that having visual awareness alone does not. We are, Wittgenstein writes, "interested in the concept [of noticing an aspect; that is, of discursively informed experience]

22 The remark at PI 193a both notes and muddies a contrast between a more simple, accusative, "mere" visual awareness, on the one hand, and visual recognition under a concept, on the other, since it contrasts two uses of "see" on the part of an already competent language-user. Nor is it any part of Wittgenstein's project to trace a material-causal history of concept acquisition. Normal visual perception on the part of competent language-users just is conceptually structured. But as Wittgenstein later notes, recognitive visual awareness involves "a modified concept of sensation" (PI 209h) from that which we might reasonably take other chordate mammals to possess. 
and its place among the concepts of experience" [seine Stellung in den Erfahrungsbegriffen] (PI 193e).

That is to say, seeing-as involves a different kind of experience, or experience in a different sense than having sensory awareness alone. Thus it is, Wittgenstein writes, "not part of perception" or "does not belong to perception" [Das "Sehen als ..." gehört nicht zur Wahrnehmung] (PI 197a) - there is more to it than takes place in sensory awareness alone. "And for that reason it is like seeing and again not like"; it "seems half visual experience, half thought"; "if you are having the visual experience expressed by the exclamation ['Now I see it as a ...'], you are also thinking of what you see" (PI 197a,d,c). When I suddenly recognize [erkenne] an acquaintance in a crowd, "is this a special sort of seeing? Is it a case of both seeing and thinking? or an amalgam [eine Verschmelzung] of the two, as I should almost like to say?" (PI 197h). Unlike mere sensing, seeing-as "demands imagination" or "requires power of imagination" [braucht es Vorstellungskraft] (PI 207h).

Within the fusion of seeing and thinking that is noticing an aspect, there are not two separable stages: first the perception, then the concept application. It is all immediate within the act of seeing-as. "No squeezing, no forcing [of a perceived object into an interpretation held apart and ready for it] took place here" (PI 200e). "So we interpret [what we notice an aspect of], and see it as we interpret it" (PI 193f).

What Wittgenstein calls "the 'continuous seeing' [stetigen Sehen] of an aspect" (PI 194b) is, for us who have come to be able to use language, the normal form of seeing. It is distinguished from explicitly noticing an aspect shift, or what Wittgenstein calls "the 'dawning' of an aspect" [das Aufleuchten eines Aspekts; its flashing or lighting up] (PI 194). The philosophical interest of this latter experience of the dawning of an aspect is that it makes evident, to and for us, who are now already conceptually conscious, something of what the experience of coming to be discursively aware of things is like.

The dawning of an aspect is not just a matter of "perceptual" or "mental" or "neural" events occurring in me. Crucially, it involves my actively placing the object seen in a context of comparisons: seeing "a likeness" [eine Ähnlichkeit; a similarity] (PI 193a), not just seeing an object. For example, when I see the duck-rabbit as a rabbit, then I would, if I were asked to explain my perception, set about "pointing to all sorts of pictures of rabbits, [and I] should perhaps have pointed to 
real rabbits, talked about their habits, or given an imitation of them" (PI 194d; see also 196a ff.). I set the object seen in a certain field of comparisons, within my very act of seeing.

This setting of the object seen within a field of comparisons is something I do in relation to other objects and pictures of objects in the world. What Wittgenstein calls the "organization" [die Organisation] (PI $196 \mathrm{~b}$ ff.) that I bring to the seeing of an object as such-and-such is not any framework or pattern "inside" my mind or brain. It is, rather, an organization or arrangement that I see in or among the things that I discursively see. When I am able to achieve such an organization or arrangement of the objects of my experience, then I have a power to respond to things that I had previously lacked. When I say, "Now I see it as a ..." then "the very expression which is also a report of what is seen, is here a cry of recognition" [ein Ausruf des Erkennens] (PI 198a). There is a kind of triumph in accession to felt power in the entry into concept-suffused perception. ${ }^{23}$ Now I can and do "describe what I am seeing differently" (PI 202b). I can actively connect this with that, within an organized field, rather than having sensory experience simply "come to me." I can and do now turn my attention on this or that, attend to this or that, notice or see that this is (like) that.

How do I do this? Again, not through the occurrence of "inner processes" alone of any kind, but through picking up on resemblances and on patterns of attention to them that are associated with words. "The substratum of this experience [of noticing an aspect, and so also of coming to 'see discursively' at all] is the mastery of a technique" (PI $208 \mathrm{e})$. It is the mastery of the technique of attention to comparisons, of seeing likenesses, that makes discursive experience possible:

"Now he's seeing it like this", "now like that" would only be said of someone capable [imstande] of making certain applications of the figure quite freely [with fluency; mit Geläufigkeit]. ... It is only if someone can do [kann], has learnt, is master of, such-and-such, that it makes sense to say he has had this experience. (PI 208e, 209a)

Hearing a word with understanding is like this as well. ("The importance of this concept [of aspect-blindness] lies in the

23 Compare, again, Collingwood on the emergence of a sense of self-as-agent out of mere sensory awareness, through the organization effected by picking up on patterns of attending, in The Principles of Art, 203-6, 234-41. 
connection between the concepts of 'seeing an aspect' and "experiencing the meaning of a word" " [PI 214d].) Experiencing the meaning of a word - hearing it with discursive understanding likewise involves (internalized) mastery of a technique of making connections between this word and various possible contexts of use, associated with various construals embodied in the word as a tool in use. "Hearing a word in a particular sense. How queer that there should be such a thing! Phrased like this, emphasized like this, heard in this way, this sentence is the first of a series in which a transition is made to these sentences, pictures, actions. ((A multitude of familiar paths lead off from these words in every direction))" (PI \$534). Language itself, Wittgenstein observes, is "a labyrinth of paths. You approach from one side and know your way about; you approach the same place from another side and no longer know your way about" $(P I \$ 203)$. The skill of knowing one's way about is a matter of knowing what one can do next - mastering the technique for it - in such a way that one immediately sees or hears these words as leading to these next possible responses. This kind of discursive understanding of words - knowing (in seeing and hearing) what can come next - is like understanding a theme in music: knowing what can (or even must) come next in it:

Understanding a sentence is much more akin to understanding a theme in music than one may think. ... Why is just this the pattern of variation in loudness and tempo? One would like to say "Because I know what it's all about". But what is it all about? I should not be able to say. In order to "explain" I could only compare it with something else which has the same rhythm (I mean the same pattern). (One says, "Don't you see, this is as if a conclusion were being drawn" or "This is as it were a parenthesis", etc.). (PI $\$ 5^{27}$, second and third emphases added)

One must learn actually to hear or see in the words or notes that are present in experience the possibilities (sometimes even the necessities) of further transitions to just this or that. "What happens when we learn to feel [empfinden] the ending of a church mode as an ending?" $(P I \$ 535)$. - We are then part of a form of life and able to move fluently within it, masters of a particular technique for making connections, itself internalized within the very act of attentive, discursively informed perception. 
4 .

The development of this explicit ability to hear or see in words or notes possibilities of connection to further words or notes is a matter of learning actively to do something, of developing an explicit ability out of an innate capacity on the basis of training in response to samples, within scenes of joint attentional interaction. The abilities that are thus developed are holistic, not modular. It is true that deaf children can learn language (both to "speak" ASL or another sign language, and to read and write English), and people who are unable to carry or recognize a tune can be fluent native speakers. As a result of brain injury, subjects can develop an inability to recognize faces, while retaining their linguistic abilities. To this extent, these abilities can be modularized. Nonetheless the development of any one of these abilities is not a strictly self-contained modular phenomenon. The abilities to hear words with discursive understanding, to recognize pictures as pictures of such-and-such (to see aspects), to hear a melody with understanding, to count, to recognize and respond to facial expressions, to repeat nursery rhymes, and more, all inform and feed off one another. Massive deficits in some areas tend to generate massive deficits in other areas, as in many cases of autism, in which the inability to respond to facial expressions of emotion undermines the development of language.

In moving from innate capacity to explicit ability to make connections (within the very act of discursive perception), seeing others as persons with points of view is crucial. $P I \$ \$ 536-39$ compare experiencing the meaning of a word and hearing the development of a melody with seeing timidity, say, in a face, and this comparison recurs throughout Part II, Section 11: for example, in discussions of reacting to the expression of a human face (PI 194c), of recognizing a face as timid or as sad (PI 2ogh, d), and of recognizing "a genuine loving look" on the basis of "imponderable evidence" (PI 228b-d). One must catch on to what is done by other people as they respond discursively to things, to their ways of noticing and responding to aspects. In order to move into explicitly discursive consciousness, "What has to be accepted, the given, is-so one could say- forms of life" (PI 226d).

The fluent abilities that one acquires through such acceptance, achieved via participation in joint attentional interactions, confer on 
the thus emergent subject of experience (in a new sense of "experience") a kind of power. Wittgenstein's image is that of being able to move along a path ("A multitude of familiar paths leads off from these words in every direction"), or of knowing how to go on. One becomes a subject of experience rather than only passively subject to experience. ${ }^{24}$ One is able to notice, actively, the aspects of things.

Coming to have this ability brings with it certain risks and also certain possibilities of satisfaction in the rightness of fitting words or things into contexts. The risk is that things themselves do not guarantee the aptness of connecting them one with another in a certain way. It is possible that certain (though not all) of the connections one makes will be repudiated or found opaque by others, especially when the concepts under which connections are made are abstract and "philosophical." (How can you call that love or respect or fairness or meaningful or syntactically organized or convincing?) But then it is also possible to feel satisfaction in the aspects of things that one notices and in the genuineness of the connections that are thus seen or heard. It is possible for a noticing of an aspect to take the form of an exclamation (PI 197b), involving a kind of immediate "Aha!" experience in seeing something as something.

In the exercise of this ability, there will always be some possibilities both of novel noticings (jokes? metaphors? invitations of intimacies?), and of noticings that are felt to be wayward or incoherent, by others or by oneself upon reflection (failed jokes? failed metaphors? failed invitations?). Distinct success is possible. One can see conceptually what is there to be seen. But the exercise of the abilities to see conceptually and to make connections between experiences (words, notes, faces, objects) always remains at the edges loosely bounded, at the edges quite unlike the ability to grasp "internal relations" between words and concepts that are "fixed." And the possibility of (further, other) action at the edges always surrounds action in noticing as such. ("A multitude of familiar paths lead off from these words in every direction.") Some may be blind to the aspects of things that others see, may be blind to the aspects of things that I see.

${ }^{24}$ See Robert B. Pippin's development of this distinction in his "Hegel's Ethical Rationalism" in Pippin, Idealism as Modernism (Cambridge: Cambridge University Press, 1997), 425 . 
Aspect-seeing centrally involves doing something: mastering a technique and acting according to it (or extending it), as a result of "taking to" joint attentional interactions. In so describing aspect-seeing, and in casting it as lying at the heart of discursive consciousness, Wittgenstein is defending both the priority of practice over theoretical representation and the irreducibility of agency to material processes. The ability actively and agentively to see one thing as another develops as one "takes to" a going practice. It is not and cannot be the result of material processes alone, though it is "built on top of" sensory-motor awareness that includes genuine "world-intake." Neither conceptual practice nor anyone's actively "taking to it" can be reduced to independent and self-subsistent material or mental processes.

Hence Wittgenstein's treatment of aspect-seeing offers us a way of thinking about human discursive consciousness that is neither mentalist, nor materialist, nor social constructivist, nor any kind of explanation. It is rather an elucidatory redescription of what we do when we employ concepts within acts of seeing. In developing this redescription, which includes attention to the roles of agency and interaction with other persons, Wittgenstein places the idea of a person as an agent among agents - with all the anxieties, wishes, fears, desires, moods, and possibilities of felt satisfaction that come with coming to be an explicit participant in conceptual practice - at the center of thinking about discursive consciousness. Wittgenstein's elucidatory redescription will not be to everyone's liking. It is, again, not a material explanation of how discursive consciousness arises in and through natural processes alone. It is rather, one might say, an invitation to see human mindedness, discursive consciousness, as like this: to notice its aspects. This invitation is "grounded" in a survey of the phenomena of discursiveness. It does not have the status of a command, grounded in pure rational-intellectual access to things in themselves, to see a discovered material or mental "essence." This invitational, elucidatory redescription of discursive consciousness is apt to regard itself as "one of the heirs of the subject that used to be called "philosophy" ( $B B$ 28) - an intimate offering to us of a way of looking at ourselves. 
